\title{
Performance analysis and test of a maize inter-row self-propelled thermal fogger chassis
}

\author{
Liqing Chen ${ }^{1,2}$, Pinpin Wang ${ }^{1}$, Peng Zhang ${ }^{1}$, Quan Zheng ${ }^{1,2^{*}}$, Jin $\mathrm{He}^{3}$, Qingjie Wang ${ }^{3}$ \\ (1. College of Engineering, Anhui Agricultural University, Hefei 230036, China; \\ 2. Anhui Intelligent Agricultural Machinery Equipment Engineering Laboratory, Hefei 230036, China; \\ 3. College of Engineering, China Agricultural University, Beijing 100083, China)
}

\begin{abstract}
In view of the difficulties in weeding and plant protection in the middle and late period of maize planting, this paper proposed a self-propelled thermal fogger chassis. According to the theoretical calculation and agronomic requirements for maize planting, the structure and working principles of the self-propelled thermal fogger chassis were introduced. On this basis, the multi-body dynamics model of chassis structure was established, and the chassis traction, steering and obstacle surmounting performances were also analyzed. Then the rationality and the feasibility of the design were verified through the furrow running test and test equipped with thermal fogger. Test results showed that, the traction performance improves with the decrease of soil deformation index and increase of cohesion, and when track pre-tensioning force was about $1000 \mathrm{~N}$, the machine had a good traction performance; with the decrease of the soil deformation index and the increase of cohesive force, the stability of the single side brake turn of the chassis becomes better; on the contrary, with the increase of the tightness of the crawler, the steering radius turns smaller and the steering stability becomes worse. Under heavy clay, with the pre-tensioning of $1000 \mathrm{~N}$, the machine has better steering stability and smaller turning radius. The obstacle-surmounting simulation result shows that on sandy soil road, the maximum climbing angle for the chassis is $42^{\circ}$, the height of vertical obstacle crossing is $170 \mathrm{~mm}$ and the trench width is $440 \mathrm{~mm}$. The study provides a reference for the design of plant protection machinery in the middle and late stages of maize planting.
\end{abstract}

Keywords: maize inter-rows, intelligent chassis, traction performance, steering performance, obstacle surmounting performance DOI: $10.25165 /$ j.ijabe.20181105.3607

Citation: Chen L Q, Wang P P, Zhang P, Zheng Q, He J, Wang Q J. Performance analysis and test of a maize inter-row self-propelled thermal fogger chassis. Int J Agric \& Biol Eng, 2018; 11(5): 100-107.

\section{Introduction}

In China, maize is an important food crop and feed source and plays a significant role in solving the problem of food security ${ }^{[1,2]}$. Increasing the yield per unit area and total production level in maize planting is an important way to ensure China's national food security $^{[3]}$. In the world, weeding and plant protection has been an important stage in maize production, and product quality and yield are directly affected by working performances of weeding and plant protection machinery ${ }^{[4,5]}$. In the middle and late stages of maize planting, its growth and development is the most vigorous with frequent occurrence of pests, thus pest control in the middle and late periods determines the maize output. However, because of the higher plant height, narrow row spacing and the difficulties in mechanical penetration, manual-held sprayers or large-scale high-clearance plant protection machinery are applied to spray pesticides. The manual sprayer spraying of pesticides may easily

\section{Received date: 2017-06-30 Accepted date: 2018-08-29}

Biographies: Liqing Chen, $\mathrm{PhD}$, Professor, research interest: crop protection and machinery engineering, Email: lqchen@ahau.edu.cn; Pinpin Wang, Master, research interest: crop protection and machinery engineering, Email: wangpinpin@ahau.edu.cn; Peng Zhang, Master, research interest: crop protection and machinery engineering, Email: 502145956@qq.com; Jin He, PhD, Professor, research interest: conservation tillage, Email: hejin@ cau.edu.cn; Qingjie Wang, PhD, Professor, research interest: conservation tillage, Email: wangqingjie@cau.edu.cn.

*Corresponding author: Quan Zheng, $\mathrm{PhD}$, Professor, research interest: power machinery engineering. College of Engineering, Anhui Agricultural University, Hefei 230036, China. Tel: +86-551-65786302, Email: zhengquan@ahau.edu.cn. cause poisoning and heatstroke of workers in spray drift and high-temperature operation environment ${ }^{[6,7]}$; Research in the world shows that large-scale high-clearance plant protection machinery demands a lot of energy and with low pesticide utilization rate, causing damages to crop and fields ${ }^{[8,9]}$.

To address these problems, scholars in China and abroad have conducted a great deal of studies, which mainly applied infrared detection technology ${ }^{[10,11]}$, ultrasonic ranging sensors ${ }^{[12,13]}$, machine vision and image processing technology for target recognition ${ }^{[14-16]}$, and integrated remote sensing technology, global positioning system and geographic information system in getting comprehensive information of the target, and applied the technologies in disaster prevention of fruit trees and crops to reduce pesticide abuse and insufficient drug use ${ }^{[17,18]}$, there are not many studies on inter-row walking-type plant protection machinery of maize and walking chassis structure. In this paper, a kind of self-propelled maize thermal fogger chassis was designed to realize inter-row pesticide spraying by holding remote control equipment.

\section{Structure and working principle design of self-propelled thermal fogger chassis}

\subsection{General structure}

Aiming at problems of high plant in the middle and late period of maize growth, and difficulties in drug spray for operators, by considering the agronomic requirements in plant protection, the intelligent chassis of the maize inter-row walking thermal fogger is designed. It is worth noting that maize planting spacing in China is generally $600 \mathrm{~mm}^{[19]}$, so the width of the machine is required to be less than $450 \mathrm{~mm}$. 
The structure of the intelligent chassis of the maize inter-row walking thermal fogger is shown in Figure 1, which is mainly composed of the driving part of the crawler chassis, thermal fogger part, the intelligent navigation control part and the remote control part.

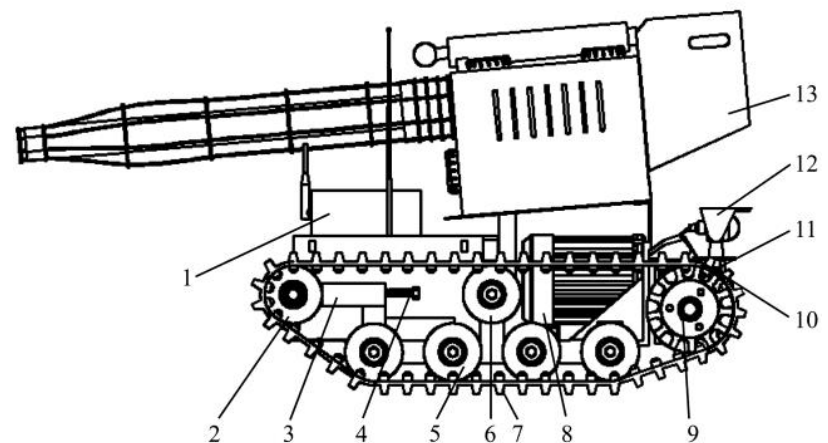

1. Controller 2. Track tensioner 3. Rack 4. Tension adjusting lever 5. Bearing wheel 6. Supporting wheel 7. Track 8. Driving motor 9. Driving wheel 10. Electromagnetic clutch 11 . Reducer 12. HD camera 13 . Thermal fogger

Figure 1 Structure of the chassis of the maize self-propelled thermal fogger

\subsection{Working principles}

When the intelligent chassis of thermal fogger is working in maize rows: the handheld terminal remote control starts the thermal fogger and the chassis driving system, and the thermal fogger begins to work; in the meantime, the chassis drives motor to divide power into two groups through a speed reducer, and send the power to both sides of the track to drive the machine forward by the electromagnetic clutch; control the spray quantity of the thermal fogger by collecting walking speed of the machine; the machine is installed with a HD camera to transmit the real-time working status is transmitted to the screen of remote control through a wireless transceiver module, then by the operator judges on the two side electromagnetic clutch for walking trajectory adjustment; besides, the machine is installed with infrared distance sensors on both sides to collect real-time working status and assist control of the working path. The working process has improved the utilization of pesticide and realized remote path control with high efficiency in costs. The working principle of the chassis of the maize self-propelled thermal fogger is shown in Figure 2.

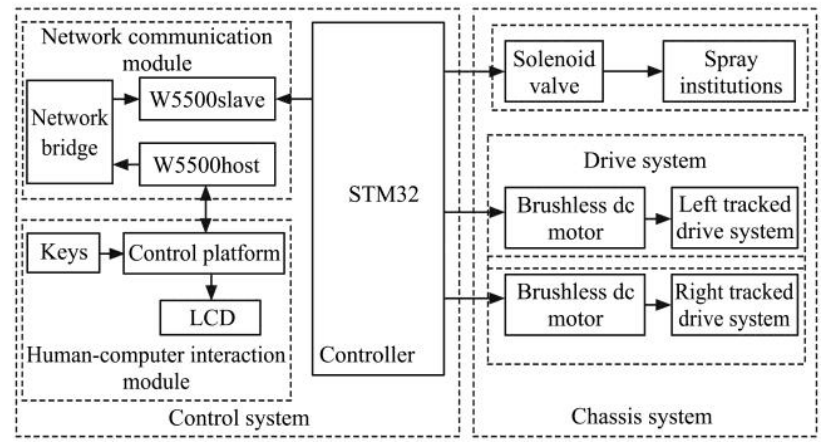

Figure 2 Working principle of the chassis of the maize self-propelled thermal fogger

\section{Self-propelled track chassis-a ground mechanics model}

\subsection{Model hypothesis}

The crawler self-propelled thermal fogger is a complex mechanical system. In this paper, in order to highlight the analysis of the chassis running system performance, the whole machine is slightly simplified: 1) Omitting the working parts, simulating the mechanism by loading the chassis system; 2) Omitting some important parts such as bolts, nuts, etc. except for crawler, other parts are considered as rigid bodies; 3) Model parameters is mainly achieved through three-dimensional measurement, calculation or experiment. The relevant parameters of the whole machine are shown in Table 1.

Table 1 Structural parameters of the crawler self-propelled thermal fogger

\begin{tabular}{|c|c|c|}
\hline Names & \multicolumn{2}{|c|}{ Parameters } \\
\hline Machine type & \multicolumn{2}{|c|}{ Rubber track } \\
\hline Overall quality $/ \mathrm{kg}$ & \multicolumn{2}{|c|}{80} \\
\hline Length $\times$ width $\times$ height $/ \mathrm{mm}$ & \multicolumn{2}{|c|}{$1300 \times 400 \times 700$} \\
\hline Basic operating speed $/ \mathrm{m} \cdot \mathrm{s}^{-1}$ & \multicolumn{2}{|c|}{ 0.1-1 Adjustable } \\
\hline Track width $/ \mathrm{mm}$ & \multicolumn{2}{|c|}{80} \\
\hline Track gauge $/ \mathrm{mm}$ & \multicolumn{2}{|c|}{300} \\
\hline Track ground length $/ \mathrm{mm}$ & \multicolumn{2}{|c|}{440} \\
\hline Drive wheel pitch diameter $/ \mathrm{mm}$ & \multicolumn{2}{|c|}{145} \\
\hline \multirow{4}{*}{ Drive motors } & Rated voltage /V & 48 \\
\hline & Rated speed $/ r \cdot \min ^{-1}$ & 2850 \\
\hline & Rated torque $/ \mathrm{N} \cdot \mathrm{m}^{-1}$ & 4.0 \\
\hline & Rated power $/ \mathrm{kW}$ & 1.2 \\
\hline \multirow{2}{*}{ Reducer } & Transmission ratio & 40 \\
\hline & Center distance $/ \mathrm{mm}$ & 50 \\
\hline
\end{tabular}

\subsection{Chassis dynamics model}

Introduce the 3D model of the crawler self-propelled thermal fog machine chassis system to the multi-body dynamics software. The chassis model is mainly composed of the crawler subsystem, the frame, the reducer and the motor. The chassis model is mainly composed of a crawler subsystem, a frame, a reducer and a motor. The crawler drive subsystem is composed of a drive wheel, a load wheel, an inducer wheel, a carrier pulley and 51 track shoes. The whole model consists of 19 rigid bodies, 16 rotating constraining pairs, and 2 fixed constraining pairs. The overall dynamics model is shown in Figure 3.

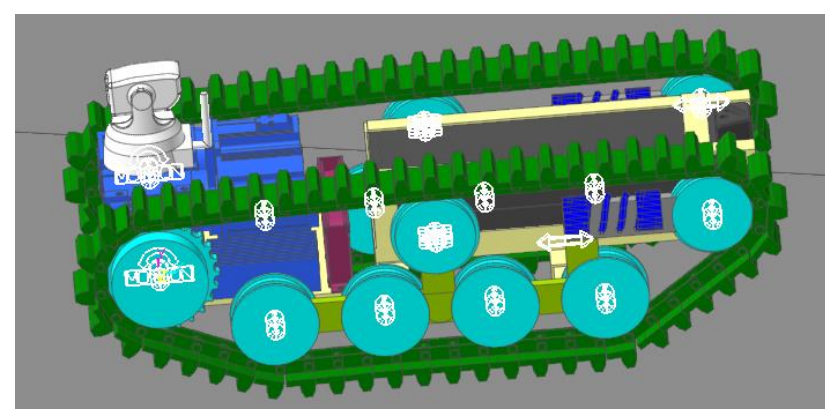

Figure 3 Dynamics model of the track self-propelled hot fog machine chassis

\subsection{Soil model}

Pressure settlement relationship of the track on the ground was proposed by the famous scholar M. G. Beck:

$$
p=\left(\frac{k_{c}}{b}+k_{\phi}\right) z_{0}^{n}
$$

where, $p$ is the unit area pressure; $k_{c}$ is the cohesive modulus of soil deformation; $k$ is the cohesive modulus of soil deformation; $b$ is the width of the load plate; $Z$ is the soil subsistence; $n$ is the soil deformation index.

Taking into account the actual working environment of the crawler type hot fog machine, sand and cohesive soils are the main soil types. Therefore, the parameters for setting the track and soil contact are shown in Table 2. 
Table 2 Parameters of ground characteristics

\begin{tabular}{lccc}
\hline \multicolumn{1}{c}{ Parameters } & Sandy soil & Clay & Heavy clay \\
\hline $\begin{array}{l}\text { Cohesion and deformation } \\
\text { modulus, } k_{c} /\left(\mathrm{N} \cdot \mathrm{mm}^{-(n+1)}\right)\end{array}$ & $4.7613 \mathrm{e}-4$ & 0.4171 & 5.1737 \\
$\begin{array}{l}\text { Internal friction and deformation } \\
\text { modulus, } k_{\phi}\left(\mathrm{N} \cdot \mathrm{mm}^{-(n+1)}\right)\end{array}$ & $7.6603 \mathrm{e}-4$ & $2.1888 \mathrm{e}-2$ & 0.63386 \\
\begin{tabular}{l} 
Soil deformation index $n$ \\
\hline
\end{tabular} & 1.1 & 0.5 & 0.13 \\
\hline
\end{tabular}

\section{Influence factors in chassis structure design}

\subsection{Traction ability of chassis}

When the chassis is walking at a constant speed on soft ground, it is driven by a driving wheel of the chassis, the function is:

STEP (Time, 0.1, 0, 0.9, 0) + STEP (Time, 1, 0, 2, -360D)

4.1.1 Influence analysis of traction capacity of the chassis on pavement parameters

The simulation results of the force analysis of single side driving wheel under the condition of sandy soil, clay and heavy clay are obtained under the condition of constant speed, as is shown in Figure 4. With the decrease of the soil deformation index and the increase of cohesion, the chassis traction ability becomes better. Under the condition of heavy clay, the variation of driving torque is great, which is mainly caused by the instability of the whole machine made by decrease of ground buffering ${ }^{[22]}$.

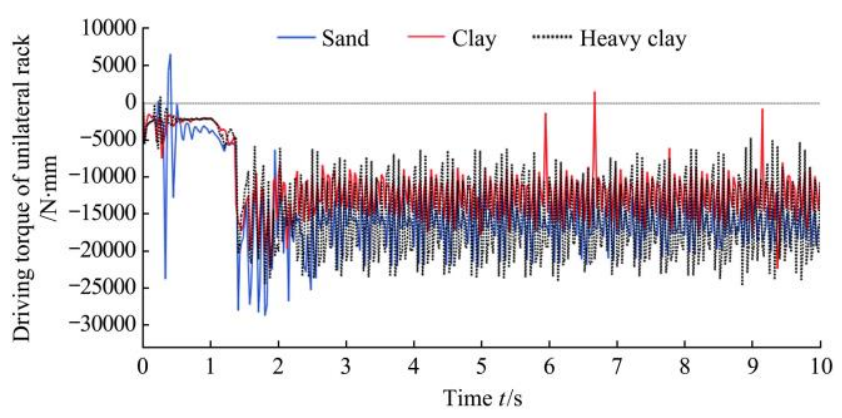

Figure 4 Simulation curve of tractive force under different ground parameters

4.1.2 Influence analysis of track tension on traction capacity of chassis

The track subsystem was loaded with pre-tensioning force of $500 \mathrm{~N}, 1000 \mathrm{~N}$ and $1500 \mathrm{~N}$ respectively, and the simulation results are shown in Figure 5. Under the condition of walking in constant speed, the chassis had stable traction capacity when pre-tensioning force was $1000 \mathrm{~N}$. The increase of pre-tensioning force could increase the resistance on the chassis, however, with the increase of pre-tensioning force to $1500 \mathrm{~N}$, the traction force increased with great variation, because of the rigid connection between bearing wheel of the chassis and the rack which lacked buffering of interactive forces with the ground and thus harmed the stability of the steering stability.

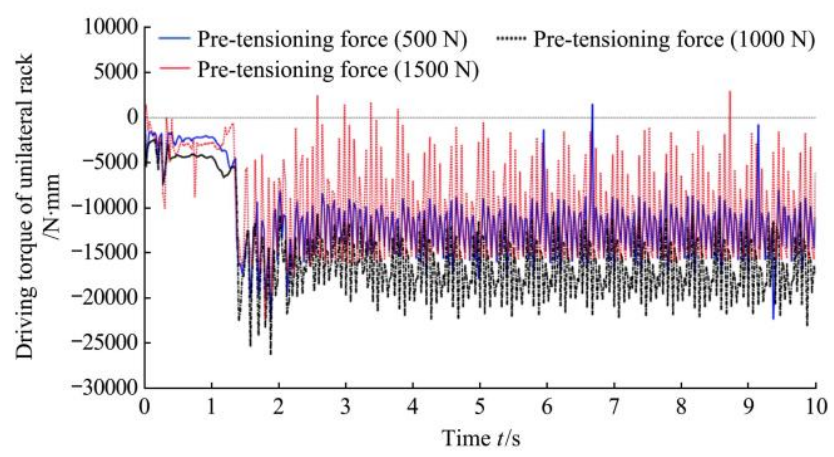

Figure 5 Traction simulation curve of different pre-tensioning forces

\subsubsection{Influence analysis of load on traction ability of chassis}

The simulation results are shown in Figure 6 when the whole machine was fully loaded $(80 \mathrm{~kg})$, half loaded $(70 \mathrm{~kg})$ and with no load $(60 \mathrm{~kg})$. The load of the chassis decreased with the pesticide spraying time, and the traction force also decreased, but the change was not obvious and the influence was relatively small. The results of the simulation show approximately that the pesticide spraying had no influence on the traction capacity of the machine.

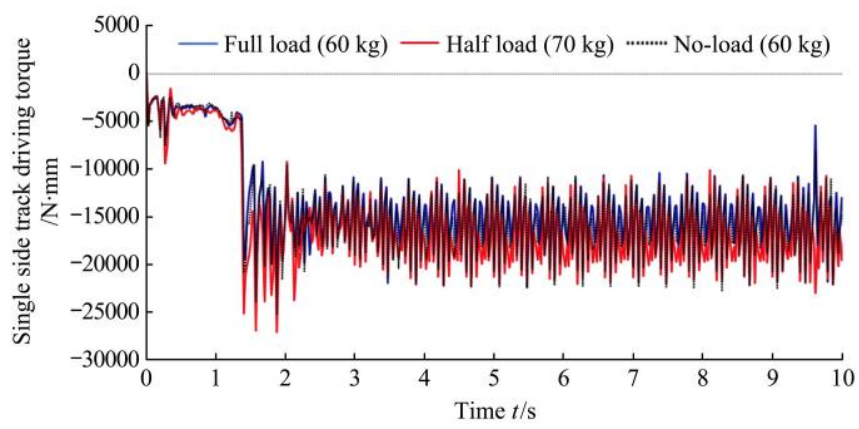

Figure 6 Simulation curve of traction force under different loads

\subsection{Chassis steering ability}

The driving environment for the machine is mainly maize rows, maize field and narrow areas, therefore, in order to ensure a smaller turning radius of the chassis, unilateral brake steering mode was applied on this machine. The steering and side driving wheel speed of the chassis on soft ground was set according to the actual speed of the machine. At $0-1 \mathrm{~s}$, the machine stayed stationary state, at 1-2 s, the chassis started and accelerated to about $0.45 \mathrm{~m} / \mathrm{s}$, at $2-4 \mathrm{~s}$, the chassis went forward at the constant speed of $0.45 \mathrm{~m} / \mathrm{s}$, at $4 \mathrm{~s}$, the braking side started till at $5 \mathrm{~s}$ when the power was off, at 5-10 s the turning side track drove the chassis and the whole machine to turn in the place.

4.2.1 Influence analysis of pavement parameters on steering capacity of the chassis

Chassis steering simulation was done under conditions of sandy soil, clay, and heavy clay. Steering capability varies by the different kinds of track slip and gliding for the interaction with different kinds of ground conditions. The simulation analysis was mainly made on steering stability of track chassis (through the centroid of the pitch angular velocity, yaw velocity and roll angular velocity) and steering driving track. The simulation results are shown in Figure 7.

Figure 7 shows that, under different ground conditions, the mean value of the centroid pitch angular velocity for the chassis on heavy clay is lower than that on clay and sandy soil and there is little fluctuation on the curve. The chassis has the largest change in roll angular velocity of centroid when driving on dry sand, there is risk of rolling if the simulation ground is not flat. On heavy clay, there is the smallest roll angular velocity in steering, with mean value similar to straight driving, indicating stable steering; the chassis has the largest yaw velocity on heavy clay after steering and the value is stable. The changes in curve on dry sand and clay are not stable, because the machine has stable steering on heavy clay and the steering of the machine itself increases the yaw angle.

Figure 8 shows that, on sandy soil, the steering radius was about $240 \mathrm{~mm}$ in maximum, and that on clay and heavy clay is about $225 \mathrm{~mm}$. However, during the $10 \mathrm{~s}$ of simulation time, the steering angle of the machine on heavy clay was about $460^{\circ}$, and the steering angle on clay was about $330^{\circ}$, that on dry sand was about $300^{\circ}$. During the process of steering, the side track subsystem caused interaction between the wheel and the track and caused track slip, 
bringing about loss of actual displacement of side track, and there was gliding of inner side of track in steering. On heavy clay ground, the slippage of the inner subsystem was the least, and the sliding rate of the side track subsystem was the lowest, so the chassis had a small steering radius and a complete steering trajectory.

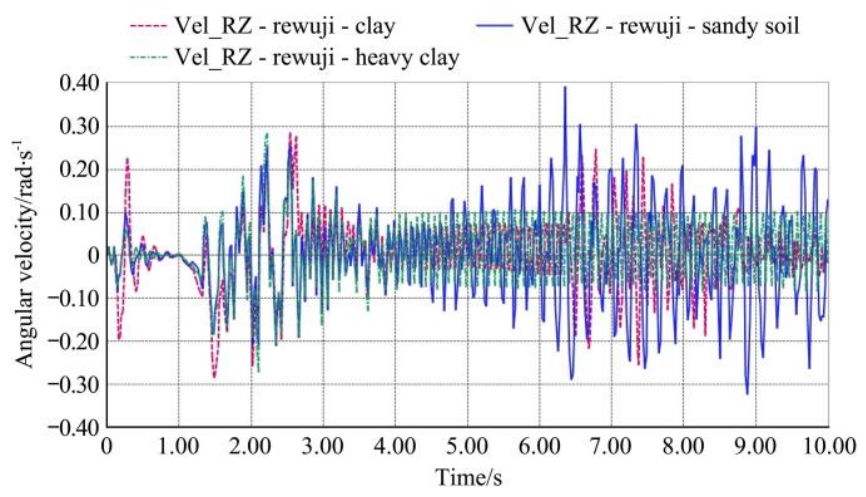

a. Pitch angular velocity of the chassis in steering on different grounds

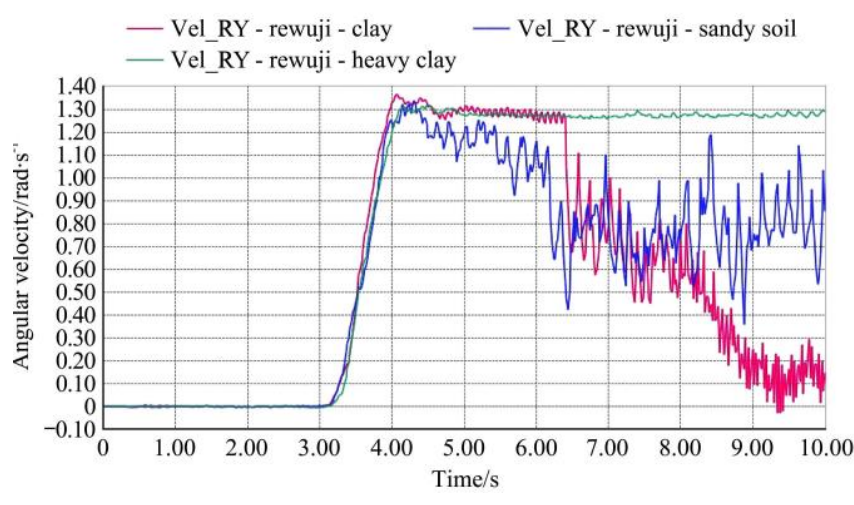

b. Yaw velocity of the chassis in steering on different grounds

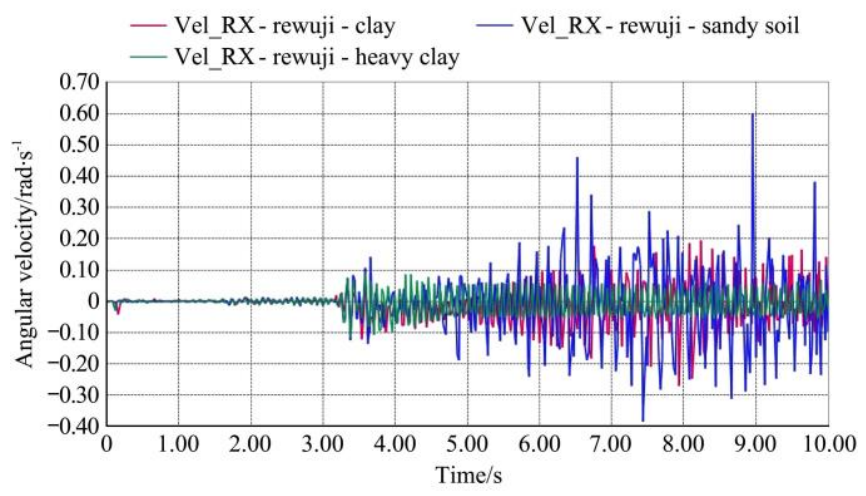

c. Roll angular velocity of the chassis in steering on different grounds

Figure 7 Simulation curve of chassis in steering stability on different grounds

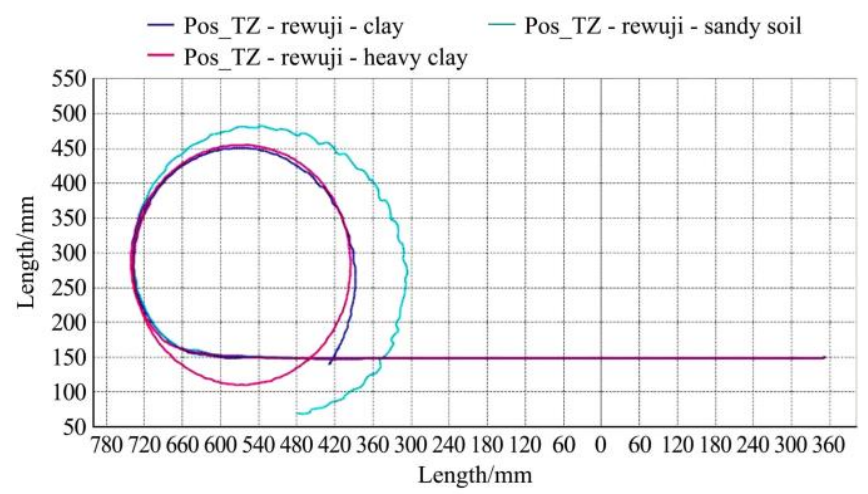

Figure 8 Simulation curve of centroid steering of the chassis on different grounds
Based on the analysis above, it can be concluded that, the chassis steering capacity increases with the decrease in the ground deformation index, the increase in internal friction deformation modulus $k_{\phi}$ and the cohesive deformation modulus $k_{c}$ increase. Namely, on heavy clay road, the steering ability is the best, and the worst on the dry sand.

4.2.2 Influence analysis of track tension on the steering ability of chassis

The machine used a rubber track, unlike the iron hinged track, the track ring itself has a certain degree of contraction, when the ring is too loose, the track will easily fall off, when the ring is too tight, the internal resistance of the machine will be increased and does harm to machine driving, also the long time status of tension may break the steel wire in the rubber track and thus damage the track. Therefore, there is great influence from track tension on the normal running of the chassis. In order to study the influence of track tension on chassis steering capacity, the pre-tensioning forces of

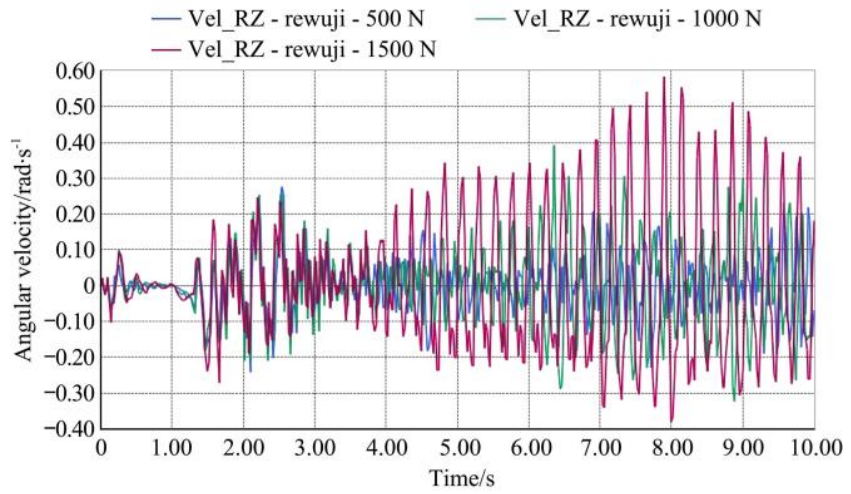

a. Pitch angular velocity of the chassis in steering under different degrees of track tension

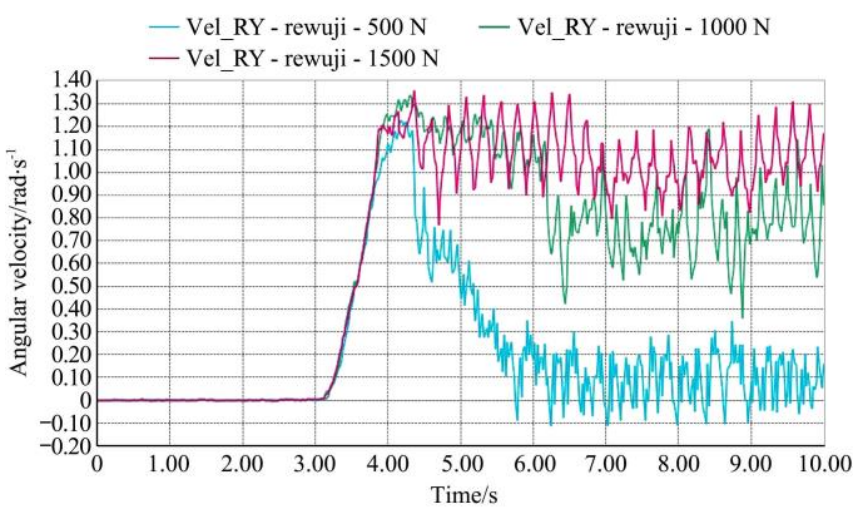

b. Yaw velocity of the chassis in steering under different degrees of track tension

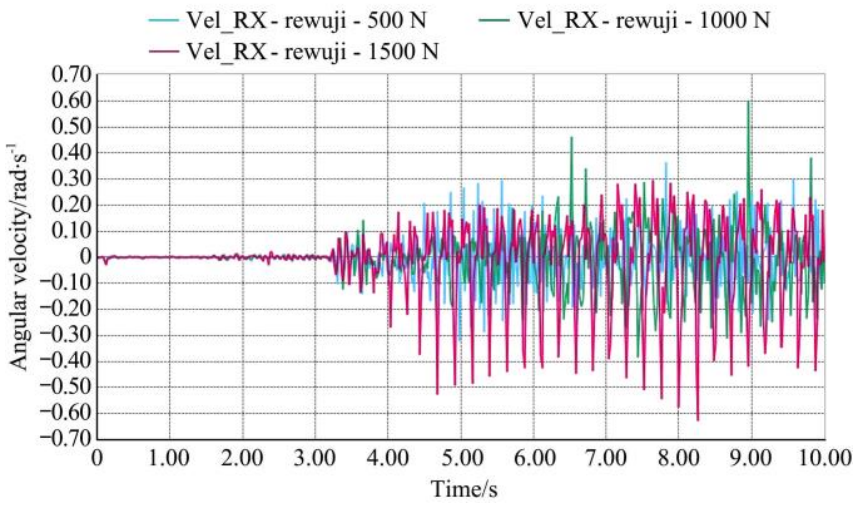

c. Roll angular velocity of the chassis in steering under different degrees of track tension

Figure 9 Simulation curve of chassis in steering stability under different degrees of track tension 
$500 \mathrm{~N}, 1000 \mathrm{~N}$ and $1500 \mathrm{~N}$ (with the tension spring compression amount of $21 \mathrm{~mm}, 42 \mathrm{~mm}$ and $63 \mathrm{~mm}$, respectively) were applied on the subsystem of the track. Clay ground was selected as the simulation pavement since it is similar to the field environment and has good steering ability. The simulation results are shown in Figures 9 and 10.

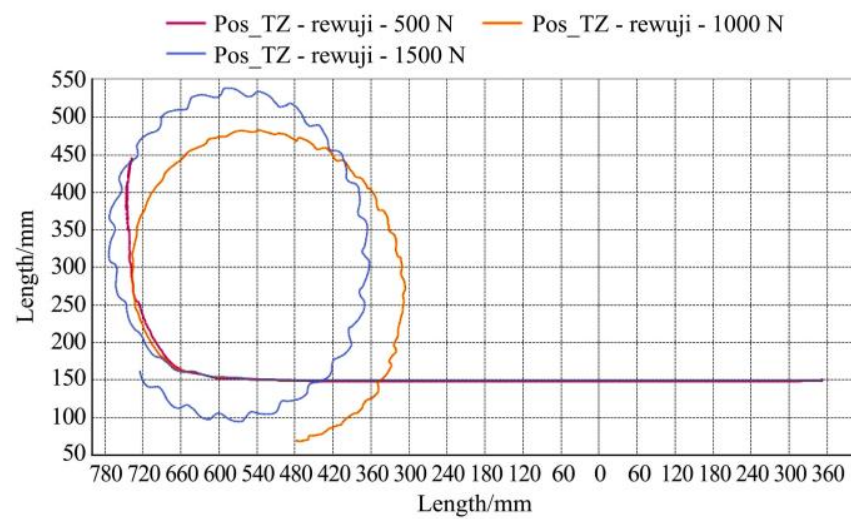

Figure 10 Simulation curve of centroid steering of the chassis under different degrees of track tension

It can be seen from Figures 9 and 10 that when the track pre-tensioning force was $500 \mathrm{~N}$, the machine had a good steering stability, the steering was relatively smooth, but the side slippage rate of the machine was high with difficulty in steering. It is mainly due to low track tension and decrease of traction capacity; when track pre-tensioning force was at $1500 \mathrm{~N}$, there was highest change variation in pitch angle, which was not good for the work of the car camera; if there were great changes in roll angle, the machine may easily roll over, there was the maximum mean yaw angle with minimum turning radius of about $225 \mathrm{~mm}$; the stability of track was better when pre-tensioning force was at $1000 \mathrm{~N}$ compared with that at $1500 \mathrm{~N}$, and the steering path radius was about $250 \mathrm{~mm}$ with much greater steering smoothness compared with that at $500 \mathrm{~N}$. The analysis shows that, the track has a good steering ability when the pre-tensioning force is $1000 \mathrm{~N}$.

\subsection{Chassis obstacle surmounting ability}

Since plant protection work in the middle and late period of maize planting mainly takes place during July to August, the field rows may form many ditches after rain erosion, and there may be some drainage areas, to meet this situation, the chassis of the machine should have good obstacle surmounting ability. Sandy soil was set as simulation ground for the chassis, both sides of the driving wheel were imposed with the same drive power, and the input function of the steering-side is as follows:

STEP (Time, 0.1, 0, 0.9, 0) + STEP (Time, 1, 0, 2, -360D)

4.4.1 Simulation analysis on chassis' ability of climbing slope

The slope of the sand pavement is set as $0^{\circ}, 25^{\circ}, 30^{\circ}, 35^{\circ}, 40^{\circ}$, $45^{\circ}$, with vertical height of $1000 \mathrm{~mm}$. According to different degrees of slope, the climbing speed of chassis is simulated and analyzed. The simulation results are shown in Figure 11.

As is shown in Figure 11, with the increase of slope, the climbing speed of the chassis reduces, in the slope climbing simulations of $25^{\circ}, 30^{\circ}, 35^{\circ}$ slope, the chassis can arrive at the top of the slope, however, after reaching the top of the hill, the chassis had little changes in velocity in climbing the slope of $25^{\circ}$, which means that the chassis can climb the slope below $25^{\circ}$. The velocity of the chassis surges sharply because of gravity at the top of slopes of $30^{\circ}$ and $35^{\circ}$, and the slippage rate is very high for slope of $40^{\circ}$ and the chassis failed to reach the slope top, so it can be concluded that the chassis can climb slopes of $25^{\circ}-40^{\circ}$ slope, but can barely climb $40^{\circ}$ slope. The chassis turned over when climbing $45^{\circ}$ slope, the maximum climbing slope is among $40^{\circ}-45^{\circ}$. Since here is little significance in finding out the precise slope angle, this paper only made a test for climbing $42^{\circ}$ slope. In simulation of climbing $42^{\circ}$ slope, the two bearing wheels in front of the chassis were suspended over the slope, therefore, if the slope degree is higher, there will be a trend of turnover for the chassis.

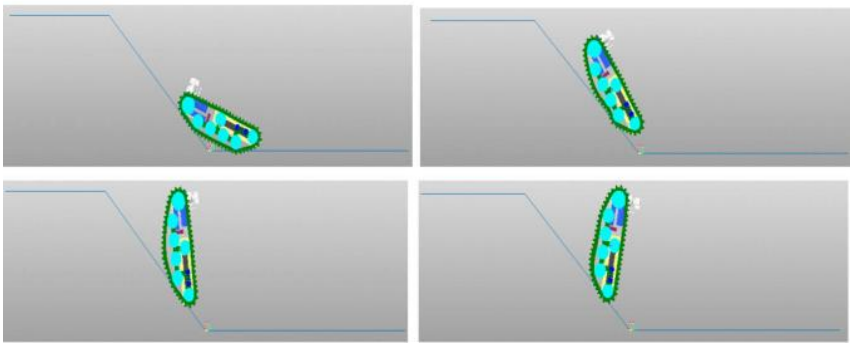

a. Rollover simulation of track chassis in climbing slope of $45^{\circ}$

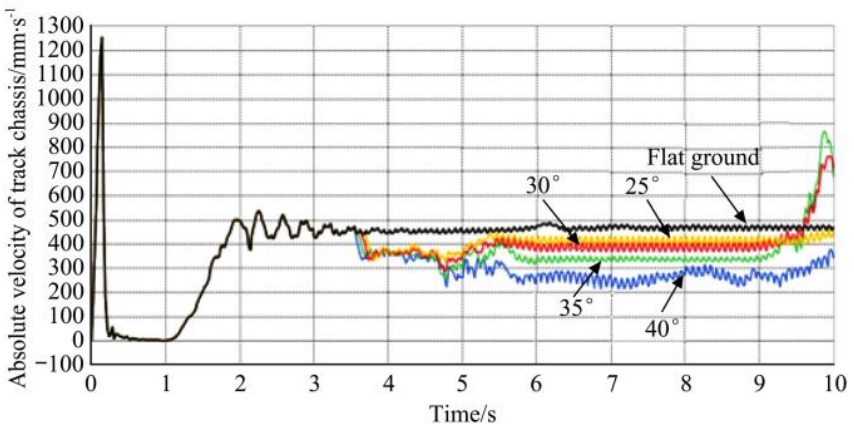

b. Absolute velocity curve of track chassis in climbing slope

Figure 11 Climbing performance simulation of track chassis

The analysis above shows that, the chassis can climb slope below $25^{\circ}$ with ease, can climb slope more than $25^{\circ}-35^{\circ}$, but can barely climb slope of $35^{\circ}-40^{\circ}$, and the maximum climbing angle is $42^{\circ}$.

4.3.2 Simulation analysis of vertical obstacle surmounting of the chassis

Three kinds of vertical obstacles of $10 \mathrm{~cm}, 15 \mathrm{~cm}$ and $20 \mathrm{~cm}$, were set up on the sandy soil to test the vertical obstacle surmounting ability of the chassis. The variation curve of the centroid pitch angle of chassis in obstacle surmounting was analyzed to show its obstacle surmounting ability. The simulation finds that, the chassis turnovers when climbing over obstacle of $20 \mathrm{~cm}$. In order to further test its obstacle surmounting ability, obstacles of $16 \mathrm{~cm}$ and $17 \mathrm{~cm}$ in height were added to test, and the simulation results are shown in Figure 12.

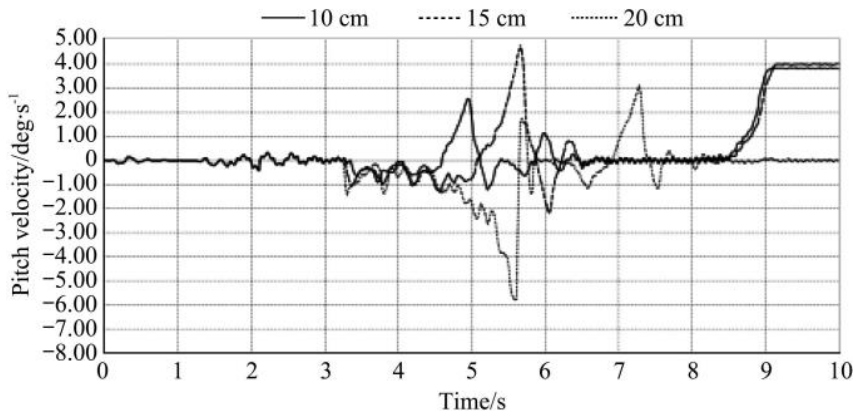

Figure 12 Simulation analysis on vertical obstacle surmounting of the chassis

Figure 12 shows that, the centroid pitch angle increases with the increase in the height of the obstacle (for example, after $8 \mathrm{~s}$, the machine drops down after climbing over the obstacles of $10 \mathrm{~cm}$, 
$15 \mathrm{~cm}$ and $16 \mathrm{~cm}$ because of short path distance, if there is no such saltation path, then the obstacle surmounting is considered a failure). The chassis could climb over obstacles below $10 \mathrm{~cm}$ with stability, could climb over obstacle of $16 \mathrm{~cm}$, but the pitch angular velocity was too high in climbing obstacles of $10 \mathrm{~cm}-15 \mathrm{~cm}$. As the centroid is at the center of the chassis, the angle between the machine and the ground is continuously increasing, when the angle reached $90^{\circ}$, the chassis would turn over. As is shown in Figure 13, the chassis rolls over when it crosses the $17 \mathrm{~cm}$ obstacle.

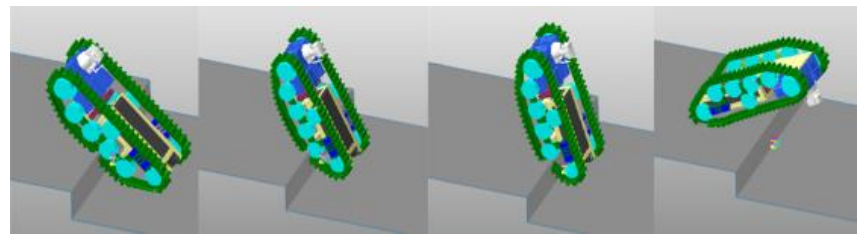

Figure 13 Screenshot of simulation of chassis in climbing over obstacle of $17 \mathrm{~cm}$

\subsubsection{Simulation analysis of chassis in striding over trenches}

When the chassis is walking in the field, the trench width and the chassis length are related to the location of centroid, generally smaller value of the distances between the centroid and two ends of the machine. Considering the flexibility of the design, the machine can switch between going forward and backward, so the centroid is set at the center of the chassis. Therefore, theoretically, the width of trench stepped over by this machine is half of the machine supporting length, which is about $440 \mathrm{~mm}$. To study the ability of chassis in stepping over trenches, three kinds of ground conditions with widths of $300 \mathrm{~mm}, 400 \mathrm{~mm}$ and $500 \mathrm{~mm}$ are set on sandy soil, and three additional conditions with widths of $430 \mathrm{~mm}, 440 \mathrm{~mm}$ and $450 \mathrm{~mm}$ are set for testing the simulation. The simulation model and results are shown in Figure 14.

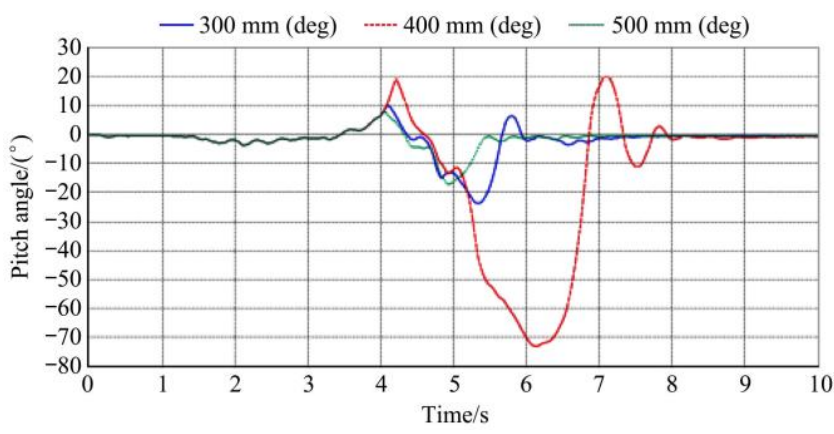

a. Pitch angle curve of simulation of chassis in striding over trenches

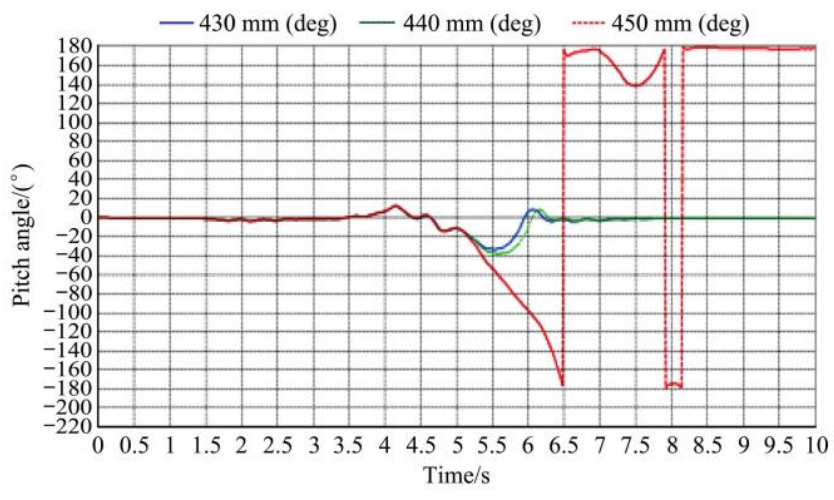

b. Pitch angle curve of simulation of chassis testing width in striding over trenches Figure 14 Simulation analysis of width of trenches stridden over by chassis

In the simulation of chassis in climbing over trenches of $300 \mathrm{~mm}, 400 \mathrm{~mm}$ and $500 \mathrm{~mm}$ in width, the pitch angle of chassis in climbing trenches of $20^{\circ}$, indicating this machine can stride over trenches with width within $400 \mathrm{~mm}$ under normal conditions. In striding over trench of $500 \mathrm{~mm}$ in width, the chassis could merely stride over the trench by touching the bottom of the trench, when the pitch angle reached $80^{\circ}$, which is a very dangerous status for the machine. After verifying the width of trenches surmounted by this machine, as is shown in Figure 14b, when the widths of trenches were $430 \mathrm{~mm}$ and $440 \mathrm{~mm}$, the pitch angle reached $40^{\circ}$, and the machine would not turn over, showing that the ability of the machine in striding over trenches was within width of $440 \mathrm{~mm}$, which could meet the requirement of driving in maize inter-rows.

\section{Field test verification}

Based on results of preliminary analysis, this study designed a sample machine and made a test at Guohe test base of Anhui Agricultural University.

\subsection{Traction capacity test}

The test combined the trailer and thermal fogger chassis with wall pulley and pulled them at a constant speed of $1 \mathrm{~m} / \mathrm{s}$, and recorded the data of traction force. The elastic coefficient of tension spring was $23.7 \mathrm{~N} / \mathrm{mm}$, then the tension bolt was adjusted to make the compression amounts of the tension spring of $21 \mathrm{~mm}$, $42 \mathrm{~mm}$ and $63 \mathrm{~mm}$. The test data are shown in Table 3 .

Table 3 shows that, there are little errors between simulation results and test results.

Table 3 Traction test and simulation comparison

\begin{tabular}{ccccc}
\hline $\begin{array}{c}\text { Working ground } \\
\text { conditions }\end{array}$ & $\begin{array}{c}\text { Spring compression } \\
\text { amount /mm }\end{array}$ & $\begin{array}{c}\text { Traction } \\
\text { force } / \mathrm{N}\end{array}$ & $\begin{array}{c}\text { Simulation } \\
\text { value } / \mathrm{N}\end{array}$ & Error /\% \\
\hline & 21 & 296.2 & 325.3 & 9.89 \\
$\begin{array}{c}\text { Maize inter-rows } \\
\text { (sandy soil) }\end{array}$ & 42 & 433.8 & 442.7 & 2.05 \\
\hline Uncultivated & 63 & 471.2 & 512.1 & 8.7 \\
$\begin{array}{c}\text { land } \\
\text { (Heavy clay) }\end{array}$ & 21 & 281.6 & 293.3 & 4.15 \\
\hline
\end{tabular}

\subsection{Steering capability test}

The test selected the diameters of three points every $120^{\circ}$ in the steering trail of side track and worked out their mean value. The steering test was done twice by turning left and right respectively. The data of the tests are shown in Table 4. Test results showed that: 1) the tighter the track was, the easier the steering would be, but the machine vibrated violently, the turning radius was $220 \mathrm{~mm}$ when compression amount of track tension was $42 \mathrm{~mm}$, showing good driving performance; 2) the steering test and simulation difference are basically consistent.

Table 4 Steering test and simulation comparison

\begin{tabular}{ccccc}
\hline $\begin{array}{c}\text { Working } \\
\text { ground } \\
\text { conditions }\end{array}$ & $\begin{array}{c}\text { Spring } \\
\text { compression } \\
\text { amount } / \mathrm{mm}\end{array}$ & $\begin{array}{c}\text { Tested steering } \\
\text { radius } / \mathrm{mm}\end{array}$ & $\begin{array}{c}\text { Simulated } \\
\text { steering radius } \\
/ \mathrm{mm}\end{array}$ & $\begin{array}{c}\text { Simulation } \\
\text { error } / \%\end{array}$ \\
\hline $\begin{array}{c}\text { Uncultivated } \\
\text { land }\end{array}$ & 21 & 325 & 265 & 22 \\
(Heavy clay) & 42 & 220 & 200 & 10 \\
\hline
\end{tabular}

\subsection{Test of obstacle surmounting ability}

The soil of maize rows may be uneven affected by seeding methods, crop growth and rain wash, thus the chassis obstacle surmounting ability is also an important evaluation index. The ground is tillage soil after manual digging and block stacking. To further test the obstacle surmounting ability of the track chassis, some fixed obstacles were randomly selected, such as stair steps, concrete slopes, as is shown in Figure 15. 


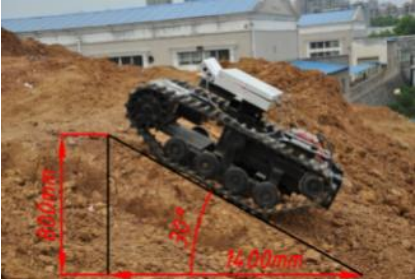

a. Track chassis climbing test

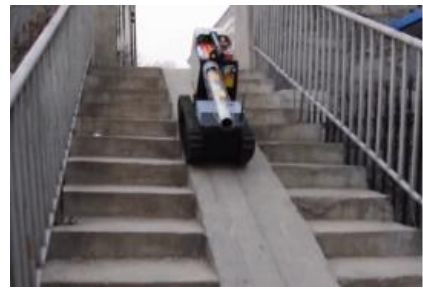

b. Test of track chassis climbing concrete slope

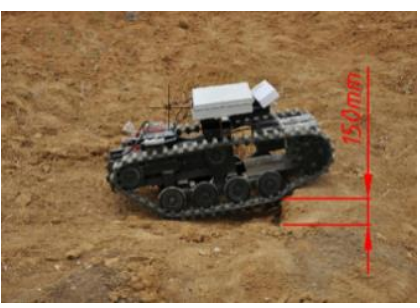

c. Vertical obstacle surmounting test of track chassis

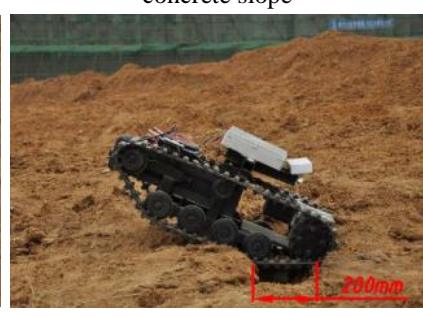

d. Test of track chassis striding over trenches
Figure 15 Test of track chassis in surmounting vertical obstacles

The test data are shown in Table 5. Test results showed that, the actual obstacle surmounting ability of the thermal fogger chassis was lower than simulation ability. The results of slope climbing test had 5\% error compared to simulation results. The track chassis could climb concrete stairs with $30^{\circ}$ slope, showing good slope climbing ability.

Table 5 Obstacle surmounting test and simulation comparison

\begin{tabular}{lccc}
\hline \multicolumn{1}{c}{ Tillage soil } & $\begin{array}{c}\text { Slope } \\
\text { angle } /\left(^{\circ}\right)\end{array}$ & $\begin{array}{c}\text { Vertical obstacle } \\
\text { surmounting height } / \mathrm{mm}\end{array}$ & $\begin{array}{c}\text { Width of } \\
\text { trenches } / \mathrm{mm}\end{array}$ \\
\hline $\begin{array}{l}\text { Simulation value of } \\
\text { obstacle surmounting }\end{array}$ & 42 & 170 & 440 \\
$\begin{array}{l}\text { Test value of obstacle } \\
\text { surmounting }\end{array}$ & 40 & 150 & 380 \\
Error & $5 \%$ & $13.3 \%$ & $15.8 \%$ \\
\hline
\end{tabular}

\section{Discussion}

1) From the above analysis and test, it can be seen that the simulation value is larger than test value for the traction capacity and obstacle surmounting ability. For the error between simulation value and test value of traction, it may be due to the fact that the soil in the test is not an ideal single soil model, or that the natural factors in the test such as wind speed. For the error between simulation value and test value of obstacle surmounting, which is caused by multiple interference factors in actual environment, for example, the obstacles set up in simulation are all smooth, but the shape and angle of the obstacles may not be very accurate in test.

2) In the steering ability, the simulation data is less than the test data. There is a certain error between them which due to the track slip and gliding cannot be ignored in actual experiment. On the other hand, due to impurities in the soil, such as the soil contains maize straw. Therefore, the turning radius will increase during the turn.

\section{Conclusions}

According to difficulties in plant protection technology in the middle and late period of maize planting and based on agronomic requirements, this research designed a kind of chassis system that is suitable for walking in rows with narrow row spacing and high plants, and can realize separation of operator and pesticide.

1) This research studied the structure parameters and working principles of chassis, established a virtual sample machine model for chassis and ground, and analyzed the relationship between pressure between track and soil, shear stress and deformation, which provided reference for further theoretical and performance analysis.

2) The analysis on the traction, steering and obstacle surmounting abilities of chassis show that, the traction performance improves with the decrease of soil deformation index and increase of cohesion, and when track pre-tensioning force is about $1000 \mathrm{~N}$, the machine has a good traction performance; chassis unilateral brake turn stability improves with the increase of soil deformation and increase of cohesion, with the increase in track tension, the turning radius becomes smaller and the steering stability becomes worse, on heavy clay with pre-tensioning of $1000 \mathrm{~N}$, the machine has good steering stability and small turning radius; obstacle-surmounting simulation results showed that the maximum climbing angle for the chassis is $42^{\circ}$ on sand road, with obstacle-surmounting height of $170 \mathrm{~mm}$ and trench-crossing width of $440 \mathrm{~mm}$. Test results showed that, this intelligent chassis has good bearing ability and can adapt to all kinds of complicated grounds and environment, thus it can meet the demand of driving in maize inter-rows.

\section{Acknowledgements}

This research was financially supported by the Special Fund of Ministry of Agriculture of China for Public Welfare Projects (No.201503136), Natural Science Fund Project in Anhui Province (No.1708085ME135) and Natural Science Major Project in Anhui Province (No.KJ2018ZD016).

\section{[References]}

[1] Zhan L, Yang H B, Lei H M. Analysis of corn water consumption, carbon assimilation and ecosystem water use efficiency based on flux observations. Transactions of the CSAE, 2016; 32(Supp.1): 88-93. (in Chinese)

[2] Zeng X T, Peng Z P, Peng Y F. Structural equation model analyzing relationship among $\mathrm{N}$ application-carbon hydrate product-grain yield of maize. Transactions of the CSAE, 2016; 32(10): 98-104. (in Chinese)

[3] Jiang J, Xiang H T, Wang L Z, Jiang L X, Wang L M, Li Z J. Reasons of grain yield increase per unit area in Heilongjiang province. Chinese Agricultural Science Bulletin, 2015; 31(36): 113-118. (in Chinese)

[4] Chahal P S, Jhala A J. Impact of glyphosate-resistant volunteer corn (Zea mays L) density, control timing, and late-season emergence on yield of glyphosate-resistant soybean (Glycine max L). Crop Protection, 2016; 81: 38-42.

[5] Jha P, Kumar V, Godara R K, Chauhan B S. Weed management using crop competition in the United States: A review. Crop Protection, 2016; 95(31): 31-37.

[6] Bueno M R, Cunha J P A R D, Santana D G D. Assessment of spray drift from pesticide applications in soybean crops. Biosystems Engineering, 2016; 154: 35-45.

[7] Zhao H Y, Xie C, Liu F M, He X K, Zhang J, Song J L. Effects of sprayers and nozzles on spray drift and terminal residues of imidacloprid on wheat. Crop Protection, 2014; 60: 78-82.

[8] Chen T H, Lu S H. Design of navigation control system for DSP based small-scale agricultural unmanned plane. Transactions of the CSAE, 2012 28(21): 164-169. (in Chinese)

[9] Wang P P, Chen L Q, Wang C L, Zheng Q. Traction performance analysis and experiment of crawler self-propelled hot fogging machine based on multi-body dynamics. IAEJ, 2017; 26(1): 119-125.

[10] Chen Z G, Wang Y G, Meng T, Sun Y K. Experiment of infrared target detection for plants pesticide spraying. Drainage and Irrigation Machinery, 2009; 27(4): 237-241, 246. (in Chinese)

[11] Deng W, Zhao C J, He X K, Chen L P, Zhang L D, Wu G W, et al. Study on spectral detection of green plant target. Spectroscopy and Spectral Analysis, 2010; 30(8): 2179-2183. (in Chinese)

[12] Brown D L, Giles D K, Oliver M N, Klassem P. Targeted spray technology to reduce pesticide in runoff from dormant orchards. Crop Protection, 2008; 27(3-5): 545-552.

[13] Song S R, Chen J Z, Hong T S, Zhang C, Dai Q F, Xue X Y. Design and 
experiment of orchard flexible targeted spray device. Transactions of the CSAE, 2015; 31(10): 57-63. (in Chinese)

[14] Malneršič A, Dular M, Širok B, Oberti R, Hočevar M. Close-range air-assisted precision spot-spraying for robotic applications: Aerodynamics and spray coverage analysis. Biosystems Engineering, 2016; 146(S1): 216-226.

[15] Oberti R, Marchi M, Tirelli P, Calcante A, Iriti M, Hočevar M, et al. Selective spraying of grapevines for disease control using a modular agricultural robot. Biosystems Engineering, 2016; 146(S1): 203-215.

[16] Yang Q H, Chang C, Bao G J, Fan J, Xun Y. Recognition and localization system of the robot for harvesting Hangzhou White Chrysanthemums. Int J Agric \& Biol Eng, 2018; 11(1): 88-95.

[17] Fu Z T, Qi L J, Wang J H. Developmental Tendency and Strategies of Precision Pesticide Application Techniques. Transactions of the CSAM, 2007; 38(1): 189-192. (in Chinese)

[18] Cao Z Y, Zhang J X, Geng C X, Li W. Control system of target spraying robot in greenhouse. Transactions of the CSAE, 2016; 26(Supp.2):
228-233. (in Chinese)

[19] Li H, Wang B, Li A J, Dong H F, Yan X G. Effects of allocations of row-spacing on maize yield under different planting densities. Chinese Agricultural Science Bulletin, 2011; 7(9): 309-313. (in Chinese)

[20] Li H, Wang B, Li A J, Dong H F. Effects of allocations of row-spacing on maize yield under different planting densities. Chinese Agricultural Science Bulletin, 2011; 27(9): 309-313. (in Chinese)

[21] Wong J Y, Chiang C F. A general theory for skid steering of tracked vehicles on firm ground. Proceedings of the Institution of Mechanical Engineers, Part D: Journal of Automobile Engineering, 2001; 215(3): 343-355.

[22] Garber M, Wong J Y. Prediction of ground pressure distribution under tracked vehicles-I. An analytical method for predicting ground pressure distribution. Journal of Terramechanics, 1981; 18(1): 1-23.

[23] Ma X G, Pan S W, You X M, Ye M, Gong X L. Mathematical models for a caterpillar driving system and its tension calculation. Journal of Vibration and Shock, 2014; 33(3): 186-190. (in Chinese) 